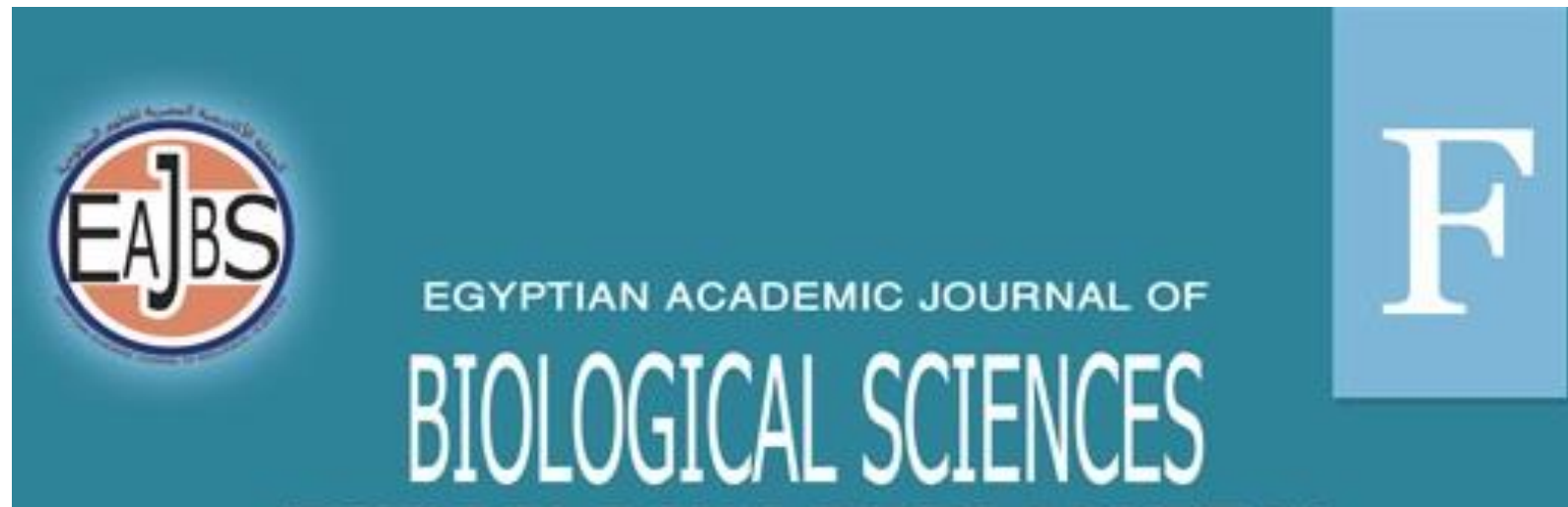

TOXICOLOGY \& PEST CONTROL
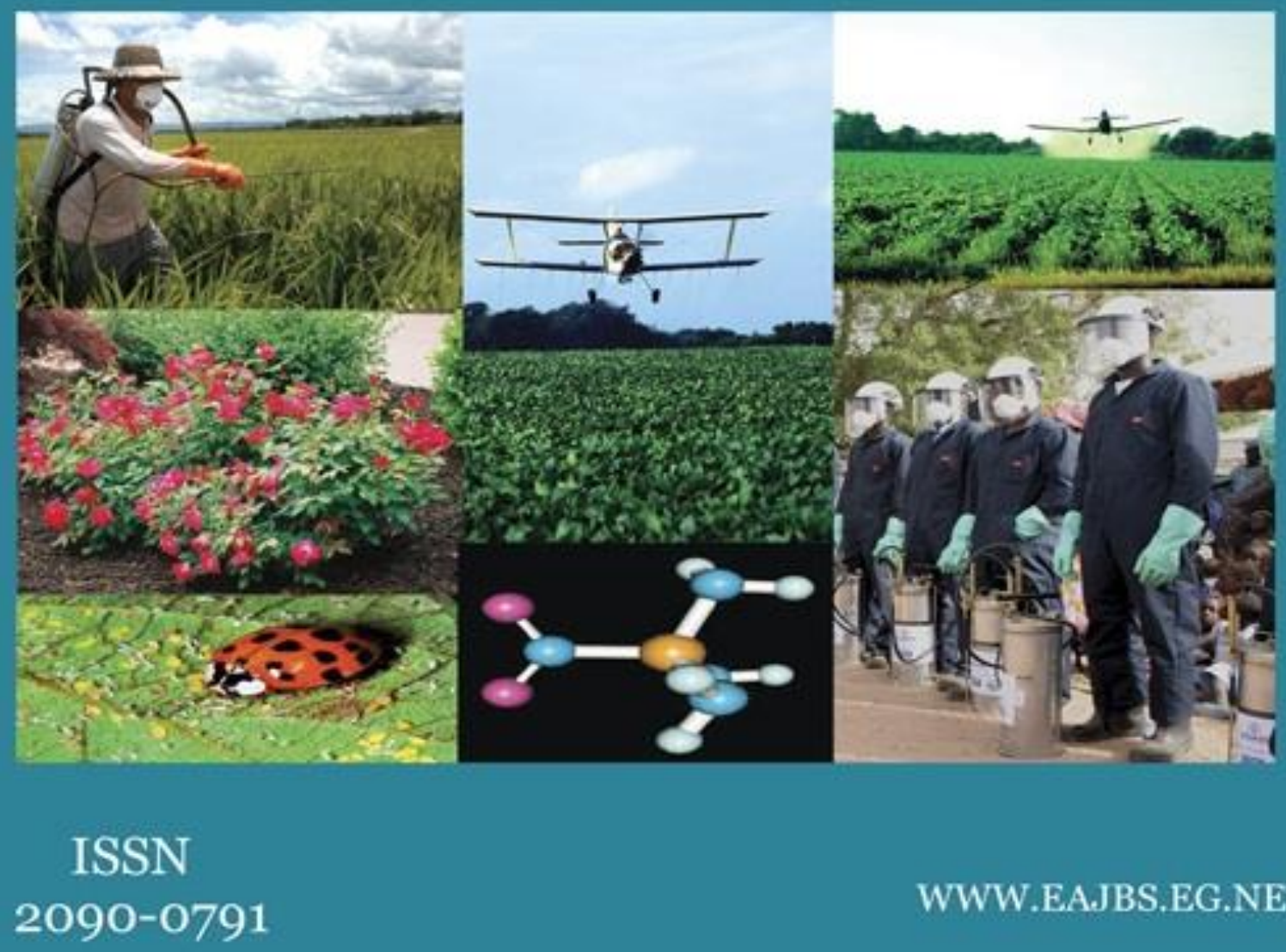

WWW.EAJBS.EG.NET

Vol. 13 No. 2 (2021)

Citation: Egypt. Acad. J. Biolog. Sci. (F.Toxicology\& Pest control) Vol.13(2)pp103-108(2021)

DOI: $10.21608 /$ EAJBSF.2021.189668 
Egypt. Acad. J. Biolog. Sci., 13(2:103-108(2021)

\begin{tabular}{|c|c|c|}
\hline $\begin{array}{c}\text { Egyptian Academic Journal of Biological Sciences } \\
\text { F. Toxicology \& Pest Control } \\
\text { ISSN: 2090 - 0791 } \\
\text { http://eajbsf.journals.ekb.eg/ }\end{array}$ & \begin{tabular}{c} 
F \\
\hline
\end{tabular} \\
\hline
\end{tabular}

\section{Efficacy of Camphor Oil and Its Nano Emulsion on The Cotton Leafworm, Spodoptera Littoralis}

Amal E. Marouf, Farid Harras, Eman A. Shehata and Ghada E. Abd-Allah

Plant Protection Research Institute, Agriculture Research Center, Dokki, Giza, Egypt

E-mail*g_nagah444@yahoo.com

ARTICLEINFO

Article History

Received: 5/6/2021

Accepted: 7/8/2021

\section{Keywords:}

Spodoptera

littoralis, camphor oil, Nano emulsion.
ABSTRACT

Laboratory experiments were tested to detect the effect of crude camphor oil and its emulsion against $2^{\text {nd }}$ instar larvae of the cotton leafworm, Spodoptera littoralis (Boisd.) (Lepidoptera: Noctuidae). Because of the problems of chemical pesticides to the environment and all organisms, the natural control replaced pesticides. In the recent years, many formulations as Nanoemulsions have been used for pest toxicity target. The results indicated that the Nano emulsion of camphor oil is the most effective material than the camphor essential oil with $\mathrm{LC}_{50} 88.67 \mathrm{ppm}$ and $1699.85 \mathrm{ppm}$ for the camphor Nano emulsion and camphor oil, respectively. So, the Nano emulsion formulation may represent a new category of natural and bio-pesticides and this should be considered in IPM programs.

\section{INTRODUCTION}

The Spodoptera littoralis (Boisd) adult (Lepidoptera: Noctuidae) lay between 300 and 500 eggs. It is the most serious pest of various crops such as cotton, tomato, and potato (Senrung et al., 2014). This pest developed resistance to many pesticides (Niranjankumar and Regupathy 2001).

Chemical control is the most common method of $S$. littoralis control due to its ease of use and reliability (Zhou et al., 2011). The natural plant products showed a strong development against a variety of insect pests (Tanzubil and Mccaffery, 1990). Essential oils may have repellent or attractive effects and had insecticidal action against pests (Rodriguez and Levin, 1975). Using Nano oils in the pest management sector could be of both ecological and economic benefit (Bixby, 2011). In recent years, some studies have shown that essential oils were toxic to different pests (Dugassa et al. 2009, Kumar et al. 2012). The camphor tree, Cinnamomum camphora (L.) J. Presl (Lauraceae), rich in camphor, occurs naturally in Asian countries (Chen et al. 2013). It has great commercial value to the cosmetic industry. Camphor exhibits a number of biological properties such as antimicrobial, anticoccidial, antiviral, antinociceptive, anticancer and insecticidal activities. In addition, it's used as a skin penetration enhancer (Chen et al. 2013). The present study aimed to find out the effect of camphor essential oil comparing with its Nano emulsion against the cotton leafworm, Spodoptera littoralis under laboratory. 


\section{MATERIALS AND METHODS}

\section{Rearing of $S$. littoralis:}

Laboratory strain of $S$. littoralis, (maintained on above 30 generations), that was initiated from freshly collected egg mass supplied from the division of cotton leafworm of Plant Protection Research Institute (PPRI), Dokki, Egypt. The larval stages were reared on castor leaves that were provided daily under constant conditions of $27 \pm 2^{\circ} \mathrm{C}$, photoperiod of $14 \mathrm{~h}$ light and $10 \mathrm{~h}$ dark and $65 \pm 5 \%$ R.H. The adult were kept separately and mated on the third day of emergence in clean jars (4 lb.) then adults were fed on $10 \%$ honey solution and fresh green leaves of tafla, Nerium oleander (L.) were provided for egg-laying.

\section{Preparation and Isolation of Essential Camphor Plant Oil:}

Essential oil (volatile oil) of camphor was extracted from the leaves of the camphor plant and extracted by steam distillation apparatus that was found in Plant Protection Institute, Mansoura, Egypt. Separated oil was dried over anhydrous sodium sulfate and stored in dark glass bottles at $4^{\circ} \mathrm{C}$ in the refrigerator until used.

\section{Preparation of Nano-Emulsions of Camphor Oil:}

The method of preparation was described by Jerobin et al. (2012). Camphor oil was diluted with distilled water to a ratio of 1:1 (oil to water), and Tween 80 was added as an emulsifier. Then, the emulsion was sonicated for 30 minutes using the ultrasonic cleaner set (model WUC-DO3H 290W) at $60 \mathrm{~Hz}$. Also, it was resonicated for 1 minute using high energy the ultrasonication probe (model VCX750) set to $750 \mathrm{~W}$ and $20 \mathrm{kHz}$, and then it was resonicated again by the ultrasonic cleaner set under cooling conditions for 30 minutes (Youssef et al., 2018).

\section{Preparation of the Stock Solution of the Tested Materials:}

Concentrations of camphor oil and the Nanoemulsion of camphor oil were prepared on basis of the tested material weight and the volume of the distilled water (w/v). Tween 80 $(0.1 \%)$ used as emulsifier. The stock concentrations were kept in glass stoppered bottles and stored under refrigeration. Such stock solutions were prepared periodically. Five diluted concentrations were used to draw the LC-P Lines for each material and four replicates were used for each concentration.

\section{Method of Application (Leaf dipping method):}

To determine the toxicity action of the tested materials, $2^{\text {nd }}$ instar larvae were used. The castor bean leaf discs were dipped into the treatments for 20 seconds and then left for air dryness. Ten larvae for each replicate were released to each leaf disc placed. The used concentrations were 500, 1000, 5000, 7500 and 10000 ppm (for camphor oil), however, the concentrations were 40, 80, 100, 250 and 500 ppm for camphor oil Nanoemulsion. The same number of leaf discs was dipped into dis. water as an untreated check. The percentage of mortality was recorded after one day, three days, five days and seven days. Data were corrected relatively to control mortality (Abbott, 1925). $\mathrm{LC}_{50}$ and $\mathrm{LC}_{90}$ values were determined using the probit analysis statistical method of Finney, 1971. Sun equation, 1950 (used to determine $\mathrm{LC}_{50}$ index).

Toxicity Index for $\mathrm{LC}_{50}=$

$\mathrm{LC}_{50}$ of the most effective compound

$\mathrm{LC}_{50}$ of the least effective compound $\mathrm{X} 100$




\section{RESULTS AND DISCUSSION}

The Efficiency of Camphor Oil and Camphor Oil Nanoemulsion Against Larvae of $S$. littoralis:

Data in Table (1) showed that the highest tested concentration $500 \mathrm{ppm}$ of nanoemulsion caused the highest mortality rate $80 \%$, while, the same concentration $500 \mathrm{ppm}$ of camphor oil caused the lowest mortality percent $33.33 \%$. The other concentrations of Nanoemulsion were 40, 80, 100 and 250 ppm recorded 36.67, 43.33, 56.67 and $66.66 \mathrm{ppm}$, respectively. However, the other concentrations of camphor oil were 1000, 5000, 7500 and $10000 \mathrm{ppm}$ recorded 43.33, 56.67, 66.67 and $86.67 \%$, respectively. Ahmed et al. (2020) evaluated the toxic effect of aniseed (Pimpinella anisum L.) essential oil (EO) and its Nano emulsion (NE) against the red flour beetle Tribolium castaneum and proved that the Nano emulsion had the highest effect than the essential oil. This result agreed with the obtained results.

Table 1: Mortality $\%$ of $2^{\text {nd }}$ instar larvae of S. littoralis treated with camphor oil and camphor oil nanoemulsion under laboratory conditions.

\begin{tabular}{|c|c|c|c|c|c|c|}
\hline \multirow{2}{*}{ Treatments } & \multirow{2}{*}{$\begin{array}{l}\text { Conc. } \\
\text { (ppm) }\end{array}$} & \multicolumn{4}{|c|}{ Mortality after treatments \% } & \multirow{2}{*}{$\begin{array}{c}\text { Total } \\
\text { Mortality \% }\end{array}$} \\
\hline & & One day & Three days & Five days & Seven days & \\
\hline \multirow{5}{*}{$\begin{array}{c}\text { Camphor } \\
\text { oil }\end{array}$} & 500 & 3.33 & 10 & 10 & 10 & 33.33 \\
\hline & 1000 & 10 & 10 & 10 & 13.33 & 43.33 \\
\hline & 5000 & 13.33 & 13.33 & 16.67 & 13.33 & 56.67 \\
\hline & 7500 & 20 & 13.33 & 13.33 & 20 & 66.67 \\
\hline & 10000 & 30 & 20 & 20 & 16.67 & 86.67 \\
\hline \multirow{5}{*}{$\begin{array}{l}\text { Camphor } \\
\text { oil nano } \\
\text { emulsion }\end{array}$} & 40 & 6.67 & 13.33 & 10 & 6.67 & 36.67 \\
\hline & 80 & 13.33 & 10 & 10 & 10 & 43.33 \\
\hline & 100 & 16.67 & 20 & 10 & 10 & 56.67 \\
\hline & 250 & 20 & 23.33 & 13.33 & 10 & 66.66 \\
\hline & 500 & 23.33 & 30 & 26.67 & 10 & 80 \\
\hline
\end{tabular}

Our results also agreed with Nadia et al. (2019) who tested the toxicity effects of four essential oils peppermint, thyme, camphor and sage oils against the fourth instar larvae of Agrotis ipsilon and their nano emulsions, they indicated the highest toxicity of nano emulstions than the essential oils.

Efficiency and Toxicity Index of The Tested Materials Against $2^{\text {nd }}$ Instar Larvae larvae of S. littoralis:

The results in Table (2) and Fig. (1) indicated that $\mathrm{LC}_{50}$ for Nano- emulsion of camphor oil was $88.67 \mathrm{ppm}$. While $\mathrm{LC}_{50}$ of the camphor oil was $1699.85 \mathrm{ppm}$. Also, LC 90 was 1389.67 and 46370.88 ppm for the Nanoemulsion of camphor oil and bulk camphor oil, respectively. The slope value was 1.072 and 0.893 for the Nano- emulsion of camphor oil and the camphor oil, respectively. The value of $\mathrm{LC}_{90} / \mathrm{LC}_{50}$ was 15.67 and 27.28 for the nano-emulsion of camphor oil and bulk camphor oil, respectively. The highest slope value or the lowest $\mathrm{LC}_{90} / \mathrm{LC}_{50}$ means the steepest toxicity line. Borie et al., (2014) reported that $S$. littoralis treatment with Nano-silica gave the highest toxic action at all concentrations after 15 days caused also; reduction in the biological parameters as larval and pupal duration, adult longevity and also female's fecundity. Derbalah et al., (2014) declared that Nano oils had a slight mortality rate against the newly hatched larvae of Pectionophora gossypiella. Also, Adel et al., (2014) showed that geranium essential oil Nanoparticles was more effective on both larval and pupal development, longevity, the fecundity of female and percentage of hatchability. And also, El-Shewy (2018) confirmed that Nanoemulsion of 
Jojoba oil was more effective than crude Jojoba oil when applied on $4^{\text {th }}$ instar larvae of the black cutworm, Agrotis ipsilon.

Table 2: Efficiency of camphor oil and its Nano-emulsion against $2^{\text {nd }}$ instar larvae of $S$. littoralis.

\begin{tabular}{|c|c|c|c|c|c|c|c|}
\hline Treatments & Conc. & \begin{tabular}{|c|} 
Corrected \\
mortality \\
$\%$ \\
\end{tabular} & $\mathbf{L C}_{50}$ & $\mathrm{LC}_{90}$ & $\begin{array}{l}\text { Slope } \pm \\
\text { S.D. }\end{array}$ & $\begin{array}{c}\text { Toxicity } \\
\text { index } \\
\text { LC }_{50} \\
\end{array}$ & $\mathbf{L C}_{90} / \mathbf{L C}_{50}$ \\
\hline \multirow{5}{*}{$\begin{array}{c}\text { Camphor } \\
\text { oil }\end{array}$} & 500 & 33.33 & \multirow{5}{*}{1699.85} & \multirow{5}{*}{46370.88} & \multirow{5}{*}{$\begin{array}{c}0.893 \pm \\
0.11\end{array}$} & \multirow{5}{*}{5.22} & \multirow{5}{*}{27.28} \\
\hline & 1000 & 43.33 & & & & & \\
\hline & 5000 & 56.67 & & & & & \\
\hline & 7500 & 66.67 & & & & & \\
\hline & 10000 & 86.67 & & & & & \\
\hline \multirow{5}{*}{$\begin{array}{c}\text { Camphor } \\
\text { oil nano } \\
\text { emulsion }\end{array}$} & 40 & 36.67 & \multirow{5}{*}{88.67} & \multirow{5}{*}{1389.67} & \multirow{5}{*}{$\begin{array}{c}1.072 \pm \\
0.156\end{array}$} & \multirow{5}{*}{100} & \multirow{5}{*}{15.67} \\
\hline & 80 & 43.33 & & & & & \\
\hline & 100 & 56.67 & & & & & \\
\hline & 250 & 66.66 & & & & & \\
\hline & 500 & 80 & & & & & \\
\hline
\end{tabular}

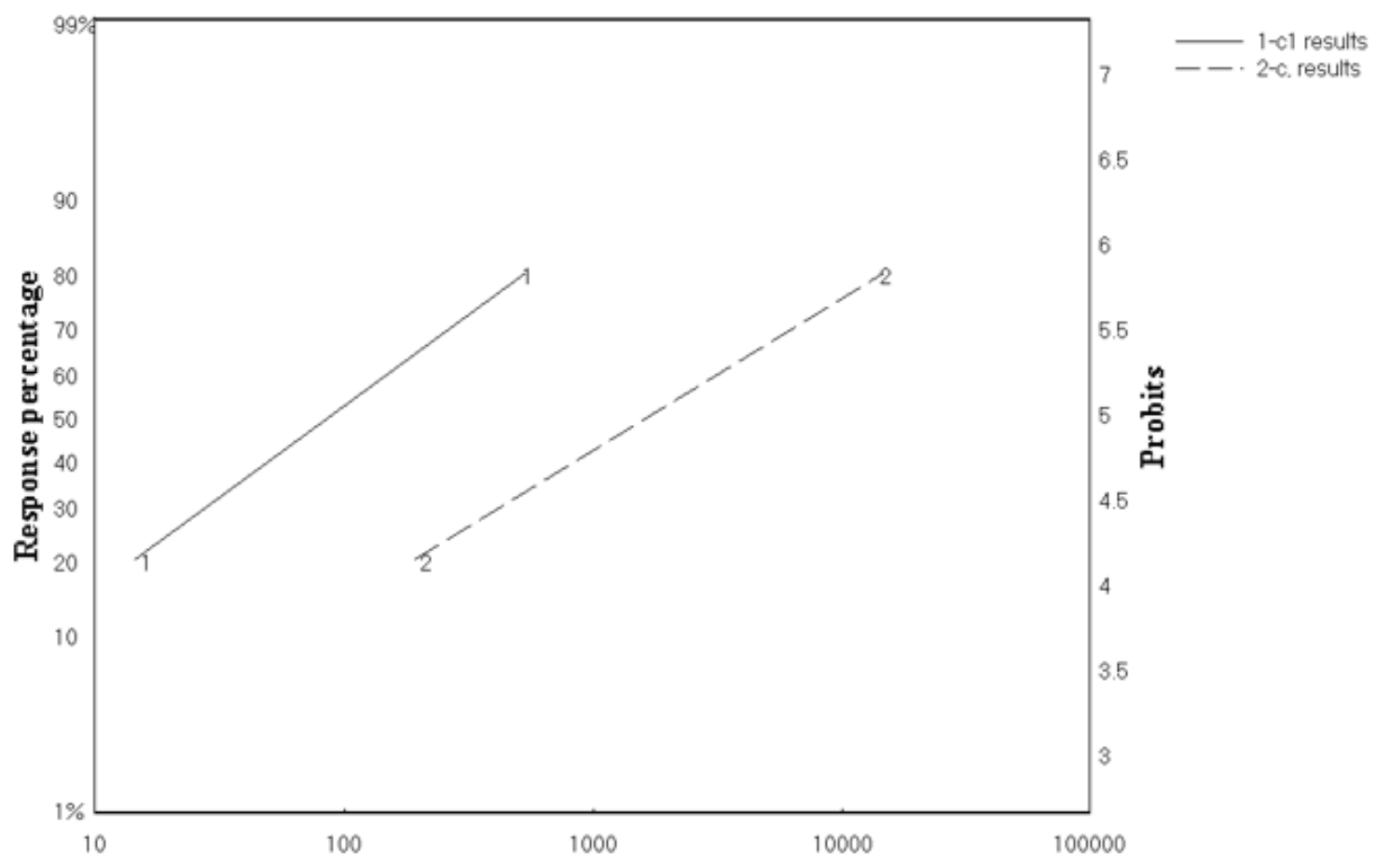

Fig. 1: LC-P line for camphor oil and its Nanoemulsion against $2^{\text {nd }}$ instar larvae of $S$. littoralis

\section{Conclusion}

The toxicity of camphor oil and its Nanoemulsion was examined against $2^{\text {nd }}$ instar larvae of $S$. littoralis and the results proved the effectiveness of the Nanoemulsion than the crude oil. 


\section{REFERENCES}

Abbott, W.S. (1925). A method of computing the effectiveness of an insecticide. Journal of Economic Entomology, 18: 265-267.

Adel, M.; W.A. Atwa; M.L. Hassan; N.Y. Salem; D.S Farghaly and S.S. Ibrahim (2014). Biological activity and field persistence of Pelargonium graveolens (Geraniales: Geraniaceae) loaded Solid lipid Nanoparticles (SLNs) on Phthorimaea operculenlla (Zeller) (PTM) (Lepidoptera: Gelechiidae). International Journal of Science \& Research, 4(11): 514-520.

Ahmed S. Hashem; Ramadan M. Marwa; Abdel-Hady A. A. Amira; Sut Stefania; Maggi Filippo and Dall'Acqua Stefano (2020). Pimpinella anisum essential oil Nanoemulsion toxicity against Tribolium castaneum shedding light on its interactions with aspartate aminotransferase and alanine aminotransferase by molecular docking. Molecules, 25: 4841- 4858.

Bixby, Brosi, A.J., (2011). Biological control of the black cutworm, Agrotis ipsilon (Lepidoptera: Noctuidae) and Entophyte mediated tritrophic interactions in turfgrass. Doctoral Dissertations, University of Kentucky.

Borie, H.A.; M.F El-Samahy; O.A. Galal and A.F. Thabet (2014). The efficiency of silica nanoparticles in control cotton leafworm, S. littoralis (Lepidoptera: Noctuidae) in soybean plants under laboratory conditions. Global Journal of Agriculture and Food Safety Sciences, (2) $161-168$.

Chen, W. Y., I. Vermaak, and A. Viljoen. (2013). Camphor-a fumigant during the black death and a coveted fragrant wood in ancient Egypt and Babylon - a review. Molecules, 18: 5434-5454.

Derbalah A.S, A.A. Khidr, H. Z. Moustafa and A. Taman (2014). Laboratory evaluation of some nonconrentional pest control agents against the pink bollworm, Pectinphora gossypiella. Egyptian Journal of Biological Pest Control, 24: (2) 363 - 368.

Dugassa, S., G. Medhin, M. Balkew, A. Seyoum, and T. Gebre-Michael. (2009). Field investigation on the repellent activity of some aromatic plants by traditional means against Anopheles arabiensis and A. pharoensis (Diptera: Culicidae) around Koka, central Ethiopia. Acta Tropica, 112: 38-42.

El-Shewy A.M. (2018). Efficacy of Jojoba oil compared to its Nano particles on biological and physiological aspects of Agrotis ipsilon and its histological effect on albino rats. Middle East Journal of Applied Science, 8 (4): 1404-1412.

Finney, D.J. (1971). Probit analysis. Cambridge univ., London pp 333.

Jerobin, J.; R.S. Sureshkumar; C.H. Anjali; A. Mukherjee and N. Chandrasekaran (2012). , "Biodegradable polymer based encapsulation of neem oil nano-emulsion for controlled release of Aza-A". Carbohydrate Polymers, 2012, 90: 1750- 1756.

Kumar, P., S. Mishra, A. Malik, and S. Satya (2012). Compositional analysis and insecticidal activity of Eucalyptus globulus (family: Myrtaceae) essential oil against housefly (Musca domestica). Acta Tropica, 122: 212-218.

Nadia Z. Dimetry; A.H. Amin; A.E. Bayoumi; M.A. Abdel-Raheem and Youssef A. Dalia (2019). Comparative toxicity of neem and peppermint oils Nano formulations against Agrotis ipsilon (Hufn.) larvae (Lepidoptera: Noctuidae). Journal of Botanical Research, 1 (1). DOI: https://doi.org/10.30564/jrb.v1i1.590

Niranjankumar B.V. and A. Regupathy (2001). Status of insecticide resistance in tobacco caterpillar, Spodoptera litura (Fabricius) in Tamil. Pesticide Research Journal, 13 (1): 86-89. 
Rodriguez, E. and P.H. Levin (1975). Biochemical parallelism of Repellents and at attractants in higher plants and arthropods- In: Recent advances in photochemistry biochemical interaction between plants and insects. pp: 215-270.

Senrung, A.; J. Singh; S. Sharma; T.N. Bhutia and A.K. Singh (2014). Effect of Murrayako enigii extracts on feeding and ovipositional response of Spodoptera litura (Fab.) (Lepidoptera: Noctuidae). Journal of Entomology \& Zoology Studies, 2 (3): 27-31.

Sun,Y.P. (1950). Toxicity indexes an improved method of comparing the relative toxicity of insecticides. Journal of Economic Entomology, 43: 45-53.

Tanzubil, P.B and A.R.M. Caffery (1990). Effect of azadirachtin and aqueous neem seed extracts on survival, growth and development of the African army worm, Spodoptera exempta. Crop Protection, 9:383-386.

Youssef, Dalia A.; Bayoumi, A.E.; Dimetry, N.Z.; Amin,A.H. and Hoballah, E.M., (2018). "Evaluating effect of pepper mint oil (Mentha pipreta) and its Nano formulations on some enzymatic activities and bionomics of cotton leaf worm Spodoptera littoralis ( Boisd.)" . Arab Universities Journal of Agriculture Science, Cairo, Special Issue, 26 (2C): 1977- 1991.

Zhou Z.; Z. Xu and Z. Chen (2011). Co-efficacy of a trap crop, Colocasia esculenta (L.) Schott and a biological agent, Spodoptera litura nuclear polyhedral virus on the tobacco caterpillar, Spodoptera litura (Fabricius) in the tobacco field. Pakistan Journal of Zoology, 11 (1): 134- 140. 